\title{
Aspectos del Microcrédito en su Concepción Original, en Búsqueda de Factores de Mayor Impacto en Colombia: Revisión de Tema
}

\author{
Yaneth P. Romero-Alvarez ${ }^{1}$ \\ Andrea P. Arenas-Sosa ${ }^{2}$ \\ Deivis J. Carrillo-Cantillo ${ }^{3}$ \\ Dairo E. Vergara-Bocanument ${ }^{4}$
}

\section{Resumen}

El artículo tiene como propósito revisar la bibliografía existente de las metodologías utilizadas y los resultados del impacto social de la filosofía microcrédito Grameen en Bangladesh, su país de origen, para encontrar diferencias y posibles determinantes del bajo impacto que éste ha tenido en Colombia y señalar los aspectos fundamentales para alcanzar las metas que se buscan con el microcrédito que se pueden resumir en "erradicar la pobreza". Adicionalmente, se hace referencia a los modelos de mayor éxito en Latinoamérica como referentes en similitud al caso colombiano. La información se obtuvo mediante la revisión, por palabra clave "Microcrédito", de publicaciones impresas y bases de datos en internet como Dialnet, E-Libro, CEPAL, EBSCO, entre otras, además gran parte de la información se tomó de las publicaciones del Banco Interamericano de Desarrollo (BID) tanto en lengua inglesa como española. Asimismo, se manifiestan factores que pueden llevar al éxito en las microfinanzas de acuerdo a investigaciones realizadas

1 Facultad de Ingenierías, INSTITUTO TECNOLÓGICO METROPOLITANO, yanetromero@itm.edu.co

2 Facultad de Ingenierías, INSTITUTO TECNOLÓGICO METROPOLITANO, andreaarenas4930@apolo.itm.edu.co

3 Facultad de Ingenierías, INSTITUTO TECNOLÓGICO METROPOLITANO, deiviscarrillo6671@apolo.itm.edu.co

4 Facultad de Ingenierías, INSTITUTO TECNOLÓGICO METROPOLITANO, estevanvergara@gmail.com

Fecha de recepción: 17 de Agosto de 2010

Fecha de aceptación: 29 de Febrero de 201 
por algunos autores. En general, se establece que en Colombia se pueden adoptar los principios del Banco Grameen, ya que publicaciones mencionadas en esta investigación demuestran cómo han mejorado las condiciones de vida de las personas pobres en diferentes países.

\section{Palabras clave}

Microcrédito, Microfinanzas, Instituciones Microfinancieras, pobreza.

\section{Abstract}

The paper aims to review the existing literature on the methodologies used and results of the social impact of philosophy Grameen microcredit in Bangladesh, their country original, to find differences and possible determinants of the low impact it has had in Colombia and identify key to reaching the goals that microcredit is looking for, which can be summarized as "to eradicate poverty." Additionally, this document refers to the most successful models in Latin America and similar references in the Colombian case. The information was obtained through review, keyword "Microcredit", printed publications and online databases as Dialnet, E-Book, CEPAL, EBSCO, among others, and much of the information was taken from publications Inter-American Development Bank (IDB) in both English and Spanish. Also express factors that can lead to success in microfinance, according to research by some authors. In general, states that Colombia can embrace the principles of Grameen Bank, as publications mentioned in this research show how they have improved the lives of poor people in different countries

\section{Keywords}

Microcredit, Microfinance, microfinance institutions, poverty. 


\section{INTRODUCCIÓN}

La Conferencia Internacional sobre Microcréditos, celebrada en Washington D.C. en 1997, propuso como definición para el microcrédito: "Los microcréditos son programas de concesión de pequeños créditos a los más necesitados de entre los pobres para que éstos puedan poner en marcha pequeños negocios que generen ingresos con los que mejorar su nivel de vida y el de sus familias" (Lacalle, 2001; Fernandez, 2006). El microcrédito fue concebido inicialmente por Yunus como la herramienta más eficaz para mitigar el hambre y la pobreza, potencializando el desarrollo económico (Velásquez, 2007). Asimismo, la enseñanza de Yunus se centra en cómo en cada país, en cada cultura, la estrategia funciona cuando encuentra líderes dispuestos a enfrentar el reto más allá de lo financiero (Arango, 2005). La gente de muy bajos recursos necesita más que las microfinanzas para resolver las causas y condiciones de su pobreza. Lo ideal es que los pobres tengan acceso a una combinación coordinada de servicios de microfinanzas y otros servicios de desarrollo" (Arango, 2005).

En Colombia, el principio de las microfinanzas fue acogido por varias entidades dedicadas al microcrédito, según Aristizábal (2007) estas son WWB Colombia, Fundación Carvajal, Actuar Famiempresas, Microempresas de Antioquia y Fundación Santo Domingo, que promueven el acceso al crédito y los demás servicios financieros a las familias de menores ingresos, micro, pequeñas y medianas empresas, y emprendedores. Sin embargo, el dinamismo en el sector financiero colombiano no ha sido el esperado, ya que no han realizado grandes esfuerzos por adquirir, ni por promocionar esta modalidad (Ortíz, 2009), las cifras son desalentadoras ya que según Serrano (2009) a Octubre de 2008 el microcrédito sólo representaba el $0,9 \%$ de la cartera de crédito de las entidades crediticias en Colombia.

No es de extrañarse que en un ranking realizado en 2008 donde se muestran las mejores 100 IMF de Latinoamérica y el Caribe, Colombia solo participó con 3 entidades en posiciones alejadas, con FMM Popayán y WWB Cali, posicionadas en el puesto 14 y 18 (MIX, 2009), y aunque para el 2010 éstas entidades quedaron en posiciones similares, el Banco Caja social que se encontraba en la 
posición 92 pasó al quinto lugar del ranking, mostrando un avance importante en el otorgamiento del microcrédito pero solo en consumo (MIX, 2010) que se caracteriza por ser a un corto o mediano plazo, pagarse en cuotas normalmente iguales y que sirve para obtener dinero de libre de disposición, convirtiéndose en una seguridad económica temporal, mientras que el microcrédito productivo se centra en la disposición de recursos en alguna actividad que significará retornos posteriores (Mejía, 2009).

Entonces, ¿Por qué es importante adaptar en su mayoría los principios del Banco Grameen en Colombia? Según algunos estudios se ha demostrado que establecerlos ayuda a reducir la pobreza. Entre estos estudios se encuentran el del Banco Mundial en 1998, en el cual se afirma que el 5\% de los prestatarios del Banco Grameen salen de la pobreza cada año; también Acción Internacional demostró que el $60 \%$ de los microcredistas de Asociación de Grupos Solidarios (AGS) (actualmente EMPRENDER), aumentaron sus ingresos entre 10 y 50\% debido a esta práctica (Velásquez, 2007). En Colombia, de acuerdo a las cifras suministradas por (DANE y DNP, 2010), el 62\% de los habitantes son pobres, es decir 27 millones de personas pobres de las cuales 7 millones viven en la indigencia, observándose entonces la gravedad estructural y la importancia de llegar a ellos a través de lineamientos que permitan erradicar la pobreza a través de un microcrédito de fácil acceso.

El propósito de este artículo es revisar la bibliografía existente de las metodologías utilizadas y los resultados del impacto social de la filosofía microcrédito Grameen en Bangladesh, su país de origen y hacer referencia a los modelos de mayor éxito en Latinoamérica como Bancosol en Bolivia y MiBanco en Perú, con el propósito de encontrar diferencias y posibles determinantes del poco éxito que éste ha tenido en Colombia y lo lejos que está de alcanzar los "Objetivos de Desarrollo del Milenio" pactado en el año 2000 y firmado por los países miembros de Naciones Unidas en la Cumbre del Milenio (Naciones Unidas, 2000) donde una de las metas principales es erradicar la pobreza y el hambre para el año 2015. 


\section{MICROCRÉDITO, INICIO Y EVOLUCIÓN}

Partiendo de los planteamientos anteriores, los siguientes son los aspectos referenciados del microcrédito en su concepción original, el desarrollo del mismo en Latinoamérica y los resultados en Colombia:

\subsection{Filosofía del Microcrédito Banco Grameen}

El microcrédito nace en el año de 1976 como un proyecto piloto implementado por Muhammad Yunus, un docente y director del departamento de economía en la Universidad de Chittagong (Bangladesh), donde luego de ver la hambruna que azotaba a este país después de independizarse de Pakistán, cansado de la impotencia que le generaba ver morir la gente de hambre en las calles y sabiendo que dictaba a sus alumnos diariamente discursos de cómo resolver los problemas de un país a nivel socioeconómico, decidió tomar cartas en el asunto y poner en práctica toda esa teoría que él impartía en su cátedra. Nació así el Banco Grameen, el cual fue constituido con una metodología casi a la inversa de la banca convencional (Rentería, 2005), basada en el principio de que "cuanto más se tenga, mas podrá conseguir, o si tiene poco o nada, no va a conseguir ni un centavo" (Yunus, 2006). Según Yunus (1998) la banca convencional se apoya en las garantías y los avales que en el sistema Grameen no se necesitan ya que ésta es una institución dedicada a otorgar microcréditos a las personas que están por debajo del umbral de pobreza.

Es por esto que treinta años después de una imparable actividad microcrediticia que, habiendo sacado de la extrema pobreza a millones de personas, ha revolucionado por completo el mundo de las finanzas, ha subvertido el orden bancario establecido y ha contribuido a destruir decenas de tópicos acerca de la pobreza y la exclusión financiera, atrayendo a personas de todo el mundo, desde reyes y jefes de gobierno hasta banqueros, profesores de universidad, periodistas y otros muchos miles de ciudadanos que, en cuanto oyen hablar del microcrédito, en cuanto empiezan a conocerlo y a escuchar testimonios de los microcredistas, se convierten 
en fervientes defensores de una nueva concepción del mundo de las finanzas que no deja indiferente a nadie (García \& Lens, 2007).

Esto ha ocurrido en virtud de que el sistema de microcrédito Grameen se basa en la premisa de que las personas pobres tienen habilidades que han utilizado muy poco o nada hasta el momento (Yunus, 2006), dado que la condición de pobreza impide el desarrollo de las capacidades de una persona (Sen, 2000). Sen afirma que "la superación de esta condición está obvia y directamente asociada al ingreso real que la gente recibe de su contribución en el sistema productivo" (Ferullo, 2006). El Banco Grameen está convencido de que quienes crean la pobreza son las instituciones y políticas que rodean a los pobres (Yunus, 2006).

Como todo evoluciona, el Banco Grameen no es la excepción, y como está contado en el libro "El Banquero de los pobres" de Muhammad Yunus, en el año 2002, se puso en marcha una conversión de su metodología operativa de Banco Grameen a Banco Grameen II, pasando de ser una entidad que otorga solamente créditos a los más pobres a ser una entidad de microfinanzas enfocada a éstos mismos, en la que se han diseñado productos como un microseguros, cuentas para pensiones, y una modalidad de préstamo básico llamada por Yunus como autopista del microcrédito Grameen, donde Yunus (2006) expone lo siguiente: "mientras el prestatario cumpla con el calendario de devoluciones, puede avanzar sin interrupciones, fácil y cómodamente, por esa autopista del microcrédito. Si conduce bien, puede cambiar a marchas cada vez más largas" .Con esta nueva modalidad los individuos que hacen parte de un grupo no se ven afectados por el incumplimiento de alguno de sus miembros. Además existe la modalidad de flexipréstamo, diseñada para los que no puedan cumplir con sus obligaciones a los plazos pactados inicialmente y necesiten reducir su cuota a cantidades que si puedan pagar, alargando el periodo de vencimiento del préstamo (Marbán, 2005; 2007).

En la actualidad, los datos del Banco Grameen son impresionantes, desde sus inicios en 1976 hasta diciembre de 2009 ha colocado 8741 millones de dólares. El número de miembros es de aproximadamente 8 millones de personas de las cuales el $97 \%$ son mujeres; Banco Grameen colocó en promedio diariamente 3 millones de dólares en 2009, ese mismo año obtuvo una utilidad de 5 millo- 
nes de dólares (Grameen, 2010). En general, desde 1989 se han hecho 131 réplicas del modelo Grameen en 35 países con resultados muy positivos (Yunus, 2006).

\subsection{Filosofía del Microcrédito Latinoamericano}

La industria de las microfinanzas en Latinoamérica ha mostrado características que la diferencian de la actividad en Asia y África, ya que lo precursores en esta región fueron entidades sin ánimo de lucro, posicionadas principalmente en el área urbana, que enfocaron su nicho de mercado principalmente en empresas sin suficiente acceso a los servicios financieros y en general al público no bancarizado (Berger, 2006). Sin embargo, en Latinoamérica, la evolución de las microfinanzas ha sido bastante buena, de acuerdo a estimaciones recientes de las instituciones de microfinanzas de la región (Navajas \& Pedroza, 2010).

En la década de 1950 los gobiernos latinoamericanos desarrollaron políticas para combatir la pobreza, a través del financiamiento de las microempresas, con la iniciativa de que este ingreso aumentaría la productividad y, por ende, generaría empleo. Entidades gubernamentales de entonces, concedían crédito prácticamente sin garantías, a bajas tasas de interés, usualmente al sector agrícola. Sin embargo, la banca comercial se mantenía alejada de estos créditos porque los concebían de alto riesgo y con grandes costos de transacción (Barona, 2004; Villarreal, 2008)

En los años ochenta se entró en la era del financiamiento microempresarial a partir del surgimiento de entidades microfinancieras especializadas, prestando dinero en pequeñas cantidades, enfocando su nicho de mercado principalmente en mujeres microemprearias que no tenían activos para dar en garantías (Barona, 2004). Finalmente en los últimos años de los noventas se empieza a ver que los pobres necesitaban de otros servicios financieros, como el ahorro y seguros, a los cuales no tenían acceso con las instituciones existentes en ese momento, por consiguiente con el afán de corregir estas falencias se desarrollaron unos portafolios más diversificados de servicios, que incentivaban la provisión de crédito a los más pobres surgiendo las cooperativas de ahorro y crédito diferentes a las ONG (Barona, 2004). 
Entre algunos de los estudios realizados sobresalen "Los indicadores de microfinanzas en América Latina: rentabilidad, riesgo y regulación", dirigido por Sergio Navajas, en el cual se analizan y se comparan los indicadores financieros de las instituciones de microfinanzas con los de la banca tradicional. La investigación se realizó sobre seis países de Latinoamérica: Bolivia, Colombia, Ecuador, El Salvador, Nicaragua y Perú; considerando que los países seleccionados reúnen la mayoría de clientes de microfinanzas de la región (Navajas, et al., 2006). Los resultados más significativos de este estudio enuncian tres conceptos muy llamativos para el microcrédito en América Latina, estos son: (i) mientras más significativo sea la participación del microcrédito dentro de la cartera, más alta será la rentabilidad de la de la institución; (ii) no es estadísticamente significativa la incidencia de los microcréditos en la cartera vencida de microfinanzas; y, (iii) existe una relación negativa entre la participación microcrédito en la cartera y el nivel de provisiones. De esta manera, se deduce que, las IMF están aumentando su rentabilidad sin incurrir en un alto riesgo y a un costo menor.

Estos conceptos los han sabido aplicar dos entidades líderes en Latinoamérica, de quienes se hará una breve reseña a continuación. La primera es quien fuera una ONG llamada Acción Comunitaria que en 1998 a través de un proceso de upgrading se transformó en MiBanco de Perú. Un banco comercial que en 2008 fue líder en su país en la colocación de crédito para microempresas y en número de clientes en este segmento, el $66 \%$ de los microcréditos fue otorgado a mujeres, tuvo una colocación total de US\$781 millones, obteniendo una utilidad neta de US\$ 27 millones y tan sólo 1,99\% de cartera retrasada (MiBanco, 2009). Adicionalmente en el último ranking de las 100 mejores entidades de microfinanzas en América Latina ocupó el segundo lugar, debido a que presentó un crecimiento de $45,3 \%$ en los créditos a microempresas (MIX, 2009). Asimismo, MiBanco tiene un portafolio de servicios muy completo entre los cuales incluye préstamos de capital de trabajo, préstamos de consumo, financiamiento hipotecario, préstamos para mejora en el hogar y préstamos para pequeñas empresas (Berger et al., 2006). 
La segunda, es una de las grandes instituciones microfinancieras de Latinoamérica, Banco Solidario S.A. (Bancosol) de Bolivia, el cual fue creado a imagen y semejanza del Banco Grameen (Muriel, 2000); es una entidad comercial enfocada a otorgar microcréditos, microseguros y microahorros a los más pobres. Tuvo su origen en 1987 cuando inició sus operaciones como una ONG llamada PRODEM dedicada a proveer créditos a pequeños proyectos empresariales de personas de escasos recursos (Patiño, 2008), hoy en día convertido en Bancosol, es una entidad que cotiza en la bolsa de valores de Bolivia con una calificación en riesgo AAA para 2009 otorgada por Moody's Latin America por tercera vez consecutiva y entre sus principales accionistas se encuentran Accion investments in Microfinanza, Inversiones y Desarrollo, Acción Internacional, Finanzas Microempresariales S.A (FIMISA) (Moody's, 2010). Como se refleja en la Fig. 1, en los últimos años Bancosol ha tenido una importante evolución en su cartera, del año 2000 a 2009 tuvo un incremento de $351 \%$ como se muestra en el siguiente gráfico.

\section{Evolución cartera \\ (en miles de dólares)}

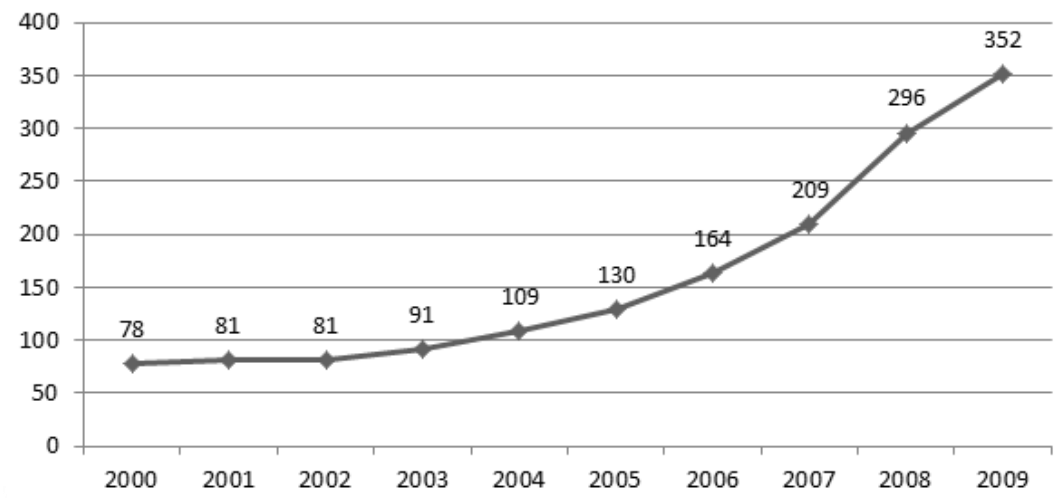

Fig. 1. Evolución cartera en dólares en términos corrientes (Koenigsfest, 2009)

Adicionalmente, en 2009 el índice de cartera en mora se mantuvo muy bajo en tan sólo 1,05\% al cierre de la gestión (Koenigsfest, 2009). 
De acuerdo al análisis de Abrams (2005), de las 21 instituciones especializadas de microfinanzas en el mundo 18 están situadas en Latinoamérica, las cuales presentaron en 2003 una rentabilidad superior a la de las 5 instituciones bancarias más destacadas a nivel global (Abrams, 2005). Con lo anterior es contradictorio la actitud pasiva que se encuentra sobre la masificación de los microcréditos en la banca tradicional, debido a que este es un mercado justo desde el punto de vista financiero: cumple exitosamente la relación de riesgo y rentabilidad que exigen los inversores profesionales (González-Vega, 2002), confirmado esto con el número de entidades de estos países en el Ranking de las 100 mejores microfinancieras latinoamericanas del 2010 (13\% Bolivia, 26\% de Perú) (MIX, 2010).

\subsection{Filosofía del Microcrédito Colombiano}

La ley 590 de 2000 significó un avance notable en el acceso de las microempresas a la financiación en el sector financiero. Antes de la ley las fuentes de financiación de las microempresas se limitaban a agiotistas y a las pocas entidades no bancarias especializadas en este segmento empresarial (Avendaño, 2006) y en la actualidad, se encuentra un sin número de entidades dedicadas al microcrédito como son WWB Colombia, Fundación Carvajal, Actuar Famiempresas, Microempresas de Antioquia, Fundación Santo Domingo, Banco Caja Social, Bancolombia, Banco Agrario Finamérica, y Cooperativa Emprender que promueven el acceso al crédito y los demás servicios financieros a las familias de menores ingresos, micro, pequeñas y medianas empresas, y emprendedores (Aristizábal, 2007; Serrano, 2009).

En efecto, el tema del acceso a los servicios financieros se ha convertido en componente transversal de las políticas de desarrollo e inclusión social implementadas por los actuales gobiernos. Iniciativas como el programa de la Banca de Oportunidades es clara muestra de la intención de hacer más accesibles a los servicios financieros para los colombianos (EMPRENDER, 2008). La Banca de las oportunidades es la materialización de los principios del Banco Grameen en Colombia surgiendo como una política encaminada a estimular el acceso del crédito a personas con un perfil 
crediticio que no era atendido por las entidades financieras tradicionales, concretándose a partir de la aprobación del decreto 3078 sancionado en septiembre de 2006 a propósito del documento 3424 presentado por el CONPES el 16 de mayo de 2006.

De esta manera los actores que prestan los servicios financieros y llegan a desembolsar directamente los recursos a las personas son distintas entidades de carácter internacional como Bancos, ONG de carácter financiero y algunas cooperativas de ahorro y crédito (Mejía, 2009). Sin embargo, según un estudio realizado por el Banco Interamericano de Desarrollo (BID) en cuatro países de Latinoamérica: Perú, Colombia, El Salvador y Paraguay, a los cuales este organismo canalizó recursos para el desarrollo de las microfinanzas a través de bancos de segundo piso a intermediarios financieros que trabajan con microempresas, se encontraron resultados altos en Perú y Paraguay, moderados en El Salvador y Bajos en Colombia (Berger et al. 2005). A septiembre de 2010 el total de la cartera bruta del sistema financiero (incluyendo las Cooperativas) ascendió a \$152'637.708, de los cuales, sólo el 2,7\% corresponden a la cartera de microcrédito (SUPERFINANCIERA, 2010).

Los programas de microcrédito en Colombia se encuentran enfocados a los moderadamente pobres o también llamados "pobres emprendedores" y no a los "más pobres entre los pobres", carentes de iniciativas de emprendimiento empresarial, ajenos a la cultura de la inversión y del ahorro, y con dificultades para constituir redes de respaldo financiero que les permitan acceder a microcréditos asociativos (Mejía, 2009). El sistema financiero no está preparado para atender el microcrédito. Se configura entonces un mercado de crédito imperfecto dado que hay racionamiento de recursos para esta línea y adicional a ellos es incompleto ya que no hay microcrédito ni financiamiento a largo plazo, esto sin tener en cuenta que el perfil del cliente "usuario de microcrédito" y por ende los riesgos en los que se incurren son demasiado altos (Aristizábal, 2007).

En un estudio de análisis de la oferta de servicios financieros en Colombia, Ecuador y Perú, se identificaron algunas variables claves que explican la ineficiencia y la inadecuación de modelos de distribución de servicios financieros en estos países: los costos de los servicios financieros básicos, la capilaridad de las redes de dis- 
tribución de servicios financieros, los métodos de análisis de crédito y los sistemas de base de datos de análisis, además del contexto normativo (Prior \& Argandoña, 2009). Partiendo de lo anterior se puede decir que en Colombia los pequeños prestatarios tienen donde financiarse, pero según Berger (2006) las entidades financieras no se han mostrado dispuestas o no están en condiciones de gestionar los riesgos que conlleva otorgar y cobrar préstamos a pequeña escala.

\section{FACTORES PRINCIPALES PARA PROMOVER UN MICROCRÉDI- TO EXITOSO EN COLOMBIA}

A diferencia de la escasa participación de Colombia, hay países que promueven mejores prácticas en las microfinanzas, como lo menciona Berger (2006). En estudios realizados en Bolivia y Perú, se demostró que el $49 \%$ de los prestatarios de Bancosol y el $27 \%$ en MiBanco se encuentran por debajo de la línea de pobreza nacional. En este sentido, se hace necesario un cambio en el enfoque de las instituciones financieras colombianas, que permita y dinamice el acceso al sistema financiero de la población más pobre que por décadas ha estado marginada o excluida de éste, logrando lo que afirma Rosenberg (2006), que se aumentaría el bienestar en los hogares de estas personas.

Los principios de Grameen se pueden adaptar a Colombia ya que en los casos exitosos Latinoamericanos han adaptado éstos, y han podido ofrecer un sistema de servicios microfinancieros gracias a las modificaciones en el marco regulatorio de cada país. Mientras que Women's World Banking Colombia una de las más exitosas entidades de microcrédito en Latinoamérica no ha podido incursionar de lleno en las microfinanzas debido a que Colombia cuenta con un marco regulatorio restringido (Rosales, 2006). Su principal obstáculo ha sido que en este país los servicios de ahorro sólo lo pueden ofrecer entidades microfinancieras especializadas, y para convertirse en una de éstas se requiere tener mínimo 200.000 clientes y un tamaño promedio en el monto de los préstamos de US\$ 1000. Esto ha impedido que WWB Colombia pase de ser una ONG a una entidad microfinanciera especializada (Berger, 2000). 
Es preciso mencionar que el proceso de transformar una ONG u otra entidad que presta servicios de microcréditos y no son vigiladas por los entes de supervisión bancaria, a ser vigiladas por este organismo se conoce como upgrading. En la década de los 90 en América Latina algunas entidades lograron esta conversión; en Boliva, Prodem se transfomó en Bancosol; en Colombia, Finansol en Finamérica y en Perú, Acción Comunitaria en MiBanco, por mencionar algunos casos. Los beneficios que se pueden obtener con este cambio son significativos: tener la posibilidad de brindar servicios financieros más completos (seguros, ahorros, etc.), fundamentales para las microempresas y personas de bajos ingresos, ayuda en la búsqueda de financiamiento, fortalecer el gobierno corporativo y aumentar la eficiencia. Este proceso es muy costoso para este tipo de empresas sin ánimo de lucro, por lo cual estas entidades están haciendo este proceso por medio de alianzas con los bancos comerciales. Es importante resaltar que no deben abandonar su nicho de mercado original ya que perderían su esencia (Berger et al. 2006).

Otro mecanismo para ampliar la oferta de microfinanzas para microempresarios y personas de bajos ingresos es el Downscaling, el cual es prestar este tipo de servicios pero a través de la banca comercial y entidades financieras ya existentes. En América Latina estas instituciones han ingresado en este mercado impulsadas principalmente por tres razones: rentabilidad de los nichos de mercado, diversificación de productos y mercados, y cumplimiento de una función social (Marulanda, 2006). En Colombia, se puede hablar de dos bancos comerciales que incursionaron en esta modalidad, el Banco Caja Social y Bancolombia. El primero desde hace 99 años se inició como una entidad para otorgar créditos a los más pobres, el $40 \%$ de los créditos de esta entidad ha sido destinado a microemprearios, su éxito se basa en abrir sucursales cerca de sus clientes y el diseño de ahorros y créditos ajustados a las necesidades de los mismos (Marulanda, 2006). El segundo banco en hacer esta incursión es el banco más grande de Colombia, en marzo de 2004 inició sus operaciones de microcréditos a través de una unidad interna (Westley, 2006).

De acuerdo a la European Commission (2000), las IMF's dedicadas al microcrédito deben ser sustentables, eficientes y eficaces. 
La sustentabilidad financiera se logra con: a) un volumen crítico de operaciones que permita una operación eficiente y efectiva; b) un diferencial satisfactorio entre la tasa activa y el costo de los fondos; c) un control de costos operativos; d) un control de pago de principal e intereses; y e) una reinversión de beneficios (tasa de capitalización) que permita aumentar el patrimonio, y en consecuencia, los montos prestados (Martínez, 2008). Entre las claves que permiten los significativos niveles de recobro de cartera son: prioridad del crédito para capital de trabajo, préstamos a corto plazo, amortizaciones frecuentes, créditos secuenciales, pocos y sencillos requisitos, agilidad en los trámites, seguimiento personalizado, garantías grupales e individuales innovadoras y accesibles, capacidad para adaptar los productos a la evolución de los negocios atendidos y la complementariedad con acciones de capacitación y asistencia técnica (Castillo \& Pozo, 2004).

Para que el microcrédito cumpla su función financiera y social de los más desfavorecidos es necesaria una implicación directa de la entidad crediticia con el beneficiario (Yunus, 2006), conocer muy bien sus necesidades y no sobreendeudarlos (Martín, 2007), y así fomentar la confianza y establecer una relación equitativa entre las Instituciones Microfinancieras (IMF) y el microcredista (Lacalle, 2002). Además, el monto concedido más los intereses deben ser devueltos por el prestatario y esto hará que el sistema funcione, también las IMF deben ser flexibles con el microcredista en caso de que surjan dificultades, como aplazar el pago de una cuota, o buscar soluciones positivas que permitan la permanencia de éste (Yunus, 2006; García \& Lens, 2007). En cuanto al riesgo, las IMF deben actuar bajo los parámetros de Basilea II, disponer de herramientas que les permitan establecer modelos de medición (scoring y ratings) con objeto de discriminar a los clientes según su perfil de riesgo, sistemas de seguimiento de riesgo vivo y modelos de evaluación de la exposición y la severidad en el riesgo crediticio (Rayo et al., 2010).

Para Muriel, las claves del éxito del microcrédito se centran en una serie de estrategias novedosas referidas por un lado, a la actividad financiera propiamente dicha, y por otro a la orientación social del Banco. La primera incluye medidas como la responsabilidad conjunta de un grupo de personas por la devolución del prés- 
tamo de cada una de ellas, el diseño de incentivos dinámicos en el desembolso y en el reembolso de fondos y la segunda estrategias que tienen como finalidad educar a sus clientes para el desarrollo, cambiar sus hábitos de comportamiento de manera que puedan escapar de su situación de pobreza a largo plazo (Muriel, 2000).

Existen otros factores determinantes para lograr el éxito del microcrédito, como es la adecuada identificación de la población objetivo para la creación y mantenimiento de la disciplina crediticia, que es una condición necesaria para la sustentación del programa. Las mujeres constituyen uno de estos grupos objetivo en los programas de microcrédito. Esto se debe entre otras razones, a que las mujeres han demostrado mejores cualidades empresariales y mejores tasas de repago que las registradas por los hombres (Martínez, 2008). El microcrédito en nuestro país no es otorgado mayoritariamente a las mujeres, como ocurre en otras regiones del mundo (Asobancaria, 2009), a diferencia de lo aplicado por el Banco Grameen donde el $97 \%$ de las prestatarias son las mujeres y en especial cabezas de familia.

En un estudio realizado se determinó que el hecho de que el solicitante sea cliente o no-cliente influye en los resultados del impacto del microcrédito, siempre y cuando, éstos participen de forma voluntaria (Kono \& Takahashi, 2010). Para Berezo (2005), el microcrédito tiene como destino fundamental financiar actividades productivas en el sector informal, pero la característica fundamental de estos destinatarios es que son pobres. Para Yunus: "la pobreza en el mundo es una creación artificial. No es parte de la civilización humana y podemos cambiar la situación. Lo único que debemos hacer es rediseñar nuestra instituciones y políticas y no habrá personas que sufrirán de pobreza" (Kliksberg, 2006).

\section{CONCLUSIONES}

De acuerdo a la presente revisión de literatura sobre el microcrédito, se determina que el modelo colombiano se sustenta en los avales y garantías bancarias, lo que dificulta el acceso de este servicio al público objetivo que son los "pobres", en especial mujeres cabezas de hogar. Se hace necesario entonces sustituir y retomar 
el microcrédito con la filosofía basada en la confianza y conciencia social, adaptando los principios de Yunus en su concepción original. Por esta razón el sistema de microcréditos requiere de entidades sustentables, eficientes y eficaces especializadas en programas de microcrédito, que estudien y conozcan público objetivo y compartan las experiencias vividas con las personas pobres y socialmente excluidas, proporcionando así elementos en conjunto para lograr el impacto deseado del microcrédito, que se conozcan a los clientes, se mida su riesgo de impago de una forma diferente a la del crédito tradicional, que se les haga un seguimiento personalizado, se incentiven y se creen con ellos mismos formas de pago grupales u otras garantías más acordes con el tipo de población y que se les capacite.

Asimismo, la revisión de la literatura internacional afirma que un medio eficaz para el desarrollo de la industria financiera es el marco regulatorio y la reforma política de un país, en donde éstos han sido tenido en cuenta se han producido grandes avances, como en Bolivia y Perú. Adicionalmente se debe hacer un esfuerzo para que se eleve el estatus de la mujer dentro de la familia, dando a ésta prioridad como beneficiarias del microcrédito, ya que en los casos exitosos internacionales representan el mayor porcentaje de sujetos de crédito, siendo mejores administradoras de los recursos y generando mejores condiciones de vida a sus familias.

Colombia está quedando rezagada en el cumplimiento de los "Objetivos de Desarrollo del Milenio" pactado en el año 2000 y firmado por los países miembros de Naciones Unidas en la Cumbre del Milenio (Naciones Unidas, 2000), donde una de las metas principales es erradicar la pobreza y el hambre para el año 2015, y Colombia en el periodo de 2002 a 2009 pasó de $53,7 \%$ a 45,5\% en los niveles de pobreza nacional disminuyendo tan sólo en $8,2 \%$, mientras que en el mismo periodo la pobreza extrema nacional tuvo únicamente una caída de $3,3 \%$ pasando de $19,7 \%$ a $16,4 \%$ (DANE \& DNP, 2010) con estos indicadores se puede deducir que no se llegará a cumplir con la meta trazada.

En general, el propósito de investigaciones de este tipo deben mostrar las verdaderas diferencias de la filosofía colombiana con respecto a la filosofía Grameen, ya que se cree que éstas han impedido que las IMF logren un mayor impacto en la reducción de la 
pobreza y la inclusión de los pobres en las microfinanzas, por lo cual se recomienda continuar esta línea de investigación hasta lograr que el microcrédito cumpla su verdadero objetivo de llegar a los más pobres en los países en vía de desarrollo.

\section{REFERENCIAS}

Abrams, J., (2005); Microfinance Profitability Index, MicroBanking Bulletin, 11, 19-21.

Arango, M.I., (2005); El microcrédito, una propuesta de esperanza, Cumbre Internacional del Microcrédito, Comfama, Medellín.

Aristizábal, R., (2007); El microcrédito como alternativa de crecimiento en la economía colombiana, Ciencias Estratégicas, 15(17), 39-57.

Asobancaria, (2009); Reporte de bancarización en Colombia, diciembre de 2009, Bogotá D.C., Colombia.

Avendaño, H., (2006); ¿Es demasiado costoso el microcrédito en Colombia?, Carta Financiera de ANIF, 133(1).

Barona, B., (2004); Microcrédito en Colombia, Estudios Gerenciales, 90, 79-102.

Berezo, J., (2005); Las microfinanzas en los países en desarrollo, Universidad Pontificia de Salamanca, España.

Berger, M., (2000); Las microfinanzas: Un mercado emergente dentro de los mercados emergentes, Banco Interamericano de Desarrollo, Washington D.C.

Berger, M., (2006); The Latin American Model, Inter-American Development Bank, Washington, D.C.

Berger, M., Beck, A., Lloreda, M., (2005); Los por mayores de las microfinanzas: Experiencias de programas de segundo piso en América Latina, Banco Interamericano de Desarrollo, Washington, D.C.

Berger, M., Otero, M., Schor, G., (2006); Pioneers in the commercialization of microfinance: The significance and future of upgraded microfinance institutions, Inter-American Development Bank, Washington D.C.

Castillo, L., Pozo, J.M., (2004); Desarrollo Local y Microcrédito, Economía y Desarrollo, 121. 
DANE y DNP, (2010); Resultados cifras de pobreza, indigencia y desigualdad 2009. Recuperado el 7 de julio de 2010, de: http://www.dane.gov.co/files/noticias/Declaracion_MESEP_2009.pdf

Dinero, (2009); Microcrédito: a buscar las bases, Revista Dinero (328), 6264.

Emprender, (2008); Boletín Microfinanciero, Bogotá.

Fernández, B., (2006); Microfinanzas en los países del Sur: surgimiento y características generales, Universidad Pontificia de Salamanca, España.

Ferullo, H., (2006); El concepto de pobreza en Amartya Sen, Valores en la Sociedad Industrial, (66), 10-16.

García, A.C., Lens, J., (2007); Microcréditos: La revolución silenciosa, Debate, Barcelona.

González-Vega, C., (2002); Criterios de evaluación de las microfinanzas, Corporación Andina de Fomento, Caracas, Venezuela.

Grameen, (2010); Recuperado el 14 de junio de 2010, www.grameeninfo.org/index.php.

Kliksberg, B., (2006); Aprendiendo de Yunus, Recuperado el 15 de noviembre de 2010, de www.aporrea.org.

Koenigsfest, K., (2009); Informe Anual de la Gerencia, Memoria Anual Bancosol, 21-49.

Kono, H., Takahashi, K., (2010); Microfinance revolution: Its effects, innovations, and challenges, The Developing Economies, 48(1), 19.

Lacalle, M., (2001); Un nuevo instrumento de financiación para luchar contra la pobreza, Revista de economía mundial, 5, 121-138.

Lacalle, M., (2002); Microcréditos: de pobres a empresarios, Ariel, España.

Marbán, R., (2005); El microcrédito en el seno del Grameen Bank, Boletín Económico de ICE (2851), 13-24.

Marbán, R., (2007); Origen, caracterización y evolución del sistema de microcréditos desarrollado por el Grameen Bank en Bangladesh, Economía Mundial, 16, 107-126.

Martín, J., (2007); Del microcrédito a las microfinanzas, Revista de Empresa, 19, 101-102. 
Martínez, A.D., (2008); El microcrédito como instrumento para el alivio de la pobreza: Ventajas y limitaciones, Cuadernos de Desarrollo Rural, 95.

Marulanda, B. (2006); Downscaling: Moving Latin American Banks into Microfinance, Inter-American Development Bank, Washington D.C.

Mejía, S.G., (2009); Análisis de los alcances y limitaciones de los programas de microcrédito como instrumentos mundiales para superar la condición de pobreza. Caso de estudio: aplicación de la metodología del banco Grameen en Colombia, Universidad Colegio Mayor de Nuestra Señora del Rosario, Bogotá, Colombia.

MiBanco, (2009); Memoria Anual 2008, Lima: MiBanco.

MIX, (2009); Microfinance Information Exchange and Fomin, Microfinanzas Américas: las 100 mejores 2009. Washington.

MIX, (2010); Microfinance Information Exchange and Fomin, Microfinanzas Américas: las 100 mejores 2010. Washington.

Moody's, (2010); Informe de revisión: Banco Solidario S.A. Buenos Aires.

Muriel, M., (2000); Microcrédito y Pobreza: un ejercicio empírico sobre el impacto del Banco Grameen, Boletin Económico de ICE 2659, 51.

Naciones Unidas, (2000); Asamblea General, Declaración del Milenio, Nueva York, 1-10.

Navajas, S., Pedroza, P., (2010); Microfinanzas en América Latina y el Caribe, Banco Interamericano de Desarrollo, Washington D.C.

Navajas, S., Navarrete, E., Simbaqueba, L., Cuevas, M., Salamanca, G., (2006); Indicadores de microfinanzas en América Latina: rentabilidad, riesgo y regulación, Banco Interamericano de Desarrollo, Washington.

Patiño, O., (2008); Microcrédito: Historia y experiencias exitosas de su implementación en América Latina, Escuela de Administración de Negocios, 63, 41-57.

Prior, F., Argandoña, A., (2009); Best practices in credit accessibility and corporate social responsibility in financial institutions, Journal of Business Ethics, 255.

Rayo, S., Lara, J., Camino, D., (2010); Un modelo de credit scoring para instituciones de microfinanzas en el marco de Basilea, Journal of Economics, Finance and Administrative, Science, 89-124. 
Rentería, L., (2005); El microfinanciamiento: una alternativa en el combate a la pobreza extrema en Sonora, Estudios Sociales, 13(25), 93-139.

Rosales, R., (2006); Regulation and Supervision of Microcredit in Latin America, Inter-American Development Bank, Washington, D.C.

Rosenberg, R., (2006); Eficacia en la ayuda de las microfinanzas: Evaluación de los proyectos de microcrédito del banco mundial y el programa de las naciones unidas para el desarrollo, Enfoques CGAP, 11-16.

Sen, A., (2000); Desarrollo y Libertad, Planeta, México.

Serrano, J., (2009); Microfinanzas e instituciones microfinancieras en Colombia, CEPAL - Serie Financiamiento del desarrollo, 212, 1-96.

Superfinanciera, (2010); Superintendencia Financiera de Colombia, Recuperado el 15 de Noviembre de 2010, de Indicadores gerenciales: http://www.superfinanciera.gov.co.

Velásquez, J., (2007); El microcrédito: Sostenibilidad financiera vs. impacto sobre pobreza, Anales de la universidad Metropolitana, 7(1), 139155.

Westley, G., (2006); Estrategias y estructuras de microfinanzas para la banca comercial. Banco Interamericano de Desarrollo, Washington D.C.

Yunus, M., (1998); Hacia un mundo sin pobreza, Andrés Bello, Barcelona.

Yunus, M., (2006); El Banquero de los pobres, Paidós, Barcelona. 